\title{
Análisis de dos décadas del catálogo editorial de la Facultad de Filosofía y Letras UBA (1990 y 2010)
}

\section{Graciela M. Giunti}

Universidad de Buenos Aires. Facultad de Filosofía y Letras. Instituto de Investigaciones Bibliotecológicas (INIBI). Buenos Aires, Argentina | gmgiunti@filo.uba.ar / https://orcid.org/oooo-0o02-2647-4023

\section{Silvia Contardi}

Universidad de Buenos Aires. Facultad de Filosofía y Letras. Instituto de Investigaciones Bibliotecológicas (INIBI). Buenos Aires, Argentina | scontardi@filo.uba.ar / https://orcid.org/oooo-0o01-8589-6472

\section{Ivalú Ramírez Ibarra}

Universidad de Buenos Aires. Facultad de Filosofía y Letras. Instituto de Investigaciones Bibliotecológicas (INIBI). Buenos Aires, Argentina | iramirezi@filo.uba.ar

\section{Resumen}

Desde su fundación en 1896 la Facultad de Filosofía y Letras de la Universidad de Buenos Aires (FFyL-UBA) asumió la tarea y el compromiso de publicar libros y fue construyendo un catálogo de cerca de 1500 títulos en toda su trayectoria. El artículo presenta un análisis de la producción editorial monográfica desde tres perspectivas: la creación intelectual, la materialidad y la difusión-circulación, cada una de las cuales agrupa diferentes variables de estudio. Se usaron métodos cuantitativos e interpretativos que permitieron, con datos concretos, aproximar una respuesta a los supuestos surgidos de una mirada general de la problemática. Se analizaron dos décadas, una del siglo pasado (1990) y otra del siglo XXI (2010). Se concluye que, sin bien los cambios de la producción editorial de la FFyL-UBA entre las dos décadas tienen variaciones tanto significativas como menores en las tres perspectivas analizadas, permiten identificar algunas tendencias y conductas consolidadas en la organización de sus publicaciones. Se identificó un incremento de la producción de una década a otra. Se observó una disminución en la monoautoría, forma predominante de escritura en la década de 1990 y se incrementó el número de autores en colaboración en la década de 2010. Se visualizan todas las disciplinas al momento de conformar el catálogo editor de la Facultad, aunque algunas con más fortaleza que otras. En las dos décadas se vislumbra el uso de títulos más convocantes y atractivos, así como también el de subtítulos para orientar sobre el tema. Las series y colecciones tanto generales como especializadas en ambas décadas mostraron ser una práctica editorial consolidada al publicarse el $80 \%$ de la producción dentro del diseño de una de ellas. El soporte preferido continúa siendo el impreso y en la última década se aprecia una clara tendencia a normalizar el sello editorial en el pie de imprenta y una presentación gráfica más atractiva. Se verificó una considerable difusión y circulación de las obras y se observaron distintas estrategias para divulgar y hacer más conocido lo publicado.

\section{Palabras clave}

Historia de la Cultura Impresa Historia de la Edición Catálogos editoriales Ediciones universitarias Universidad de Buenos Aires. Facultad de Filosofía y Letras 


\section{Analysis of two decades of the editorial catalog of the Facultad de Filosofía $y$ Letras UBA (1990 y 2010)}

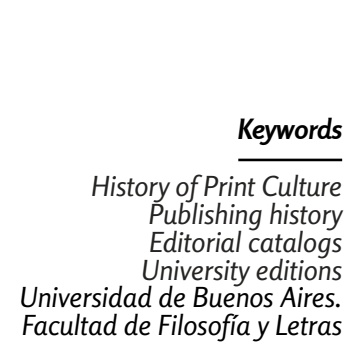

Facultad de Filosofía y Letras

\section{Abstract}

Since its foundation in 1896, the Facultad de Filosofía y Letras de la Universidad de Buenos Aires (FFyL-UBA) has committed to publishing books, having built a catalog of nearly 1500 titles throughout its history. The article presents an analysis of this books editorial production from three perspectives: intellectual creation, materiality, and dissemination-circulation, each of which contains different study variables. We used quantitative and interpretative methods and the concrete data allowed us to attempt an answer to the assumptions arising from a general view of the problem. Two decades were analyzed, one from the last century (1990) and another from the 21st century (2010). We concluded that, although the changes in the editorial production of the FFyLUBA in the two decades have both significant and minor variations in the three perspectives analyzed, they have allowed us to identify some trends and constant behaviors in the organization of its publications. An increase in production from one decade to another was identified. We observed a decrease in mono-authorship, the predominant form of writing in the 1990s, while the number of collaborating authors increased in the 2010s. All Faculty's disciplines are present on its editorial catalog, although some carry more weight than others. In the two decades the use of more compelling and attractive titles as well as subtitles to guide on the subject is evident. The general and specialized collections in both decades proved to be a consolidated publishing practice as $80 \%$ of the production was published within one of them. The preferred medium continues to be the print and in the last decade there has been a clear tendency to standardize the publishing house stamp in the imprint and to give a more attractive graphic presentation. There was a considerable dissemination and circulation of the works while different strategies to disseminate publications were observed.

Artículo recibido: 26-10-2021. Aceptado: 29-11-2021
1. Este trabajo fue realizado dentro del Proyecto FILO:CyT (FC19-031), Editar y leer en la Universidad. Una historia de la edición académica de la Facultad de Filosofía y Letras (UBA) desde la Historia de la Lectura, (Universidad de Buenos Aires. Facultad de Filosofía y Letras, Instituto de Investigaciones Bibliotecológicas. INIBI) que comenzó a mitad de 2019 y concluye en 2021 bajo la dirección de Alejandro E. Parada y Beatriz Valinoti. Una versión preliminar de estos resultados se presentó en las VI Jornadas de Intercambio y Reflexión acerca de la Investigación en Bibliotecología, realizadas en la Universidad Nacional de La Plata el 13 de agosto de 2021. < http://jornadabibliotecologia.fahce.unlp.edu.ar/ Jornadas\%202021/programa-2021/ Jornadas\%202021/actas-2021>

\section{Introducción ${ }^{1}$}

La Universidad de Buenos Aires es una entidad de derecho público y, tal como lo declara en su estatuto, tiene como objetivos esenciales la promoción, difusión y preservación de la cultura en estrecha relación con la sociedad. Es una comunidad de profesores, alumnos, nodocentes y graduados que, mediante la enseñanza, el estudio y la investigación contribuye a la resolución de los problemas argentinos en un contexto de pensamiento universal. Dentro de la función social y cultural que la caracteriza, esta Universidad lleva adelante una actividad consustancial con su misión en donde "organiza la publicación y la difusión de la labor intelectual de sus integrantes y, además, procura publicar las obras más significativas de la cultura argentina y de la cultura universal" (Universidad de Buenos Aires, 1960: 13).

Las universidades y la edición de textos académicos siempre es un tema convocante porque, como afirma Noé Jitrik, las funciones de la edición universitaria son "poner en circulación obras, autores y problemas que tienen que ver con la identidad, el valor y el futuro de la cultura nacional (...); ayudar al estudioso y al estudiante acercándole obras y autores indispensables para la formación y la investigación (...); dar a conocer los resultados del trabajo de la propia universidad, en la medida en que aporten al conocimiento general y al desarrollo de la cultura del país" (Anaya Rosique, 1989, p. 41). 
En el contexto de la estructura simbólica de las instituciones, quizá se podría considerar que las editoriales y su producción son un intento por interpretar y representar los discursos colectivos de la comunidad. Estos textos dan acceso a ideas, pensamientos, debates que fueron ocurriendo y van perfilando la historia intelectual o de las ideas tanto en la Universidad como en cada una de sus Facultades. En este sentido es importante el rol que dentro de la UBA tiene Eudeba, su destacada editorial que ha sido objeto de numerosas investigaciones; además, varias de sus Facultades han desarrollado las propias, como es el caso que nos ocupa.

En los últimos tiempos se han implementado numerosas investigaciones que estudian el campo de la edición universitaria en la Argentina desde diferentes perspectivas lo que muestra un interés por abordar esta temática en nuevas investigaciones. En esta línea están los trabajos de Dujovne, algunos de ellos junto a Sorá, que estudian las relaciones de interdependencia que se dan entre el campo editorial y el campo académico en las Ciencias Sociales y Humanas. Un aspecto que han tratado en sus investigaciones es el valor de las traducciones en el campo editorial que permite indagar sobre la circulación local de ideas provenientes de otros orígenes y otros idiomas y su relación con el papel de los editores al introducirlas en el campo académico (Dujovne, 2017; Sorá y Dujovne, 2018). En otros trabajos Dujovne se ha dedicado a tratar de estudiar la circulación de los libros editados por las editoriales universitarias y su uso concreto en el campo académico, por ejemplo, su inclusión en la bibliografía de los programas de los seminarios de los doctorados que ofrecen las Universidades argentinas. Esta acción la denomina "efectos de lectura" y le permitiría observar el impacto intelectual dentro de la agenda académica, vinculado al capital intelectual del sello editorial (Dujovne, 2018). En otro trabajo estudia las particularidades de la edición universitaria pública argentina y las transformaciones que tuvo este sector entre los años 2014 y 2019. Optó por la realización de una extensa encuesta con el objetivo de brindar una visión conjunta del campo editorial para obtener datos concretos de su desarrollo y poder identificar los problemas comunes que tienen las 35 editoriales (de 51 identificadas) que respondieron la encuesta (Dujovne, 2019).

Los trabajos de Mihal y de Centeno se han concentrado en el estudio de las ediciones universitarias argentinas y su comercialización en distintas ferias del libro (Buenos Aires, Guadalajara, FILUNI, etc.) considerando los espacios de las ferias como lugares de oportunidades para mostrar los catálogos editoriales ante un público masivo y concentrado en un tiempo acotado (Centeno, 2012; Mihal, 2020 y Mihal, 2021).

Otros autores abordan la edición de libros universitarios de alguna disciplina particular para estudiar la relación entre la disciplina y la edición universitaria como instancia de validación de las investigaciones del área, indagando de este modo la relación entre campo académico y edición universitaria como lo hace Bonacci cuando estudia los libros de Sociología publicados en la Argentina tras el retorno a la democracia (Bonacci, 2018).

Las editoriales de gestión universitaria publican libros necesarios para la institución a la que pertenecen y lo hacen, también, con la misión de trascender sus fronteras para insertar y dar a conocer su capital intelectual en la sociedad que la sustenta.

En este contexto hay que diferenciar el libro académico-científico del libro universitario. El primero es el libro que está pensado para satisfacer las demandas de los ámbitos universitario y académico, y puede ser generado tanto por editoriales que tienen fines comerciales como por editoriales universitarias. En cambio, el segundo, se refiere exclusivamente a los libros que producen las editoriales de las universidades (Úbeda, 2007). En el ámbito universitario la producción de libros es considerada como un servicio de extensión, donde lo relevante no es el valor comercial del objeto 
sino prestar un servicio a la sociedad. Con este objetivo, las publicaciones se someten a varias instancias de evaluación para producir libros de alta calidad académica y editorial en consonancia con el perfil de la demanda de sus usuarios, ya que es propio de las editoriales universitarias la proximidad con su público real o potencial (Torres Ripa, 2007). Sin embargo, una de sus falencias es la falta de registros que permitan su identificación y localización. Esto puede obedecer a múltiples razones: económicas, burocráticas, institucionales y administrativas que, no obstante, se van subsanando con la profesionalización del área editorial de las universidades que tiende a centralizar y controlar este aspecto.

Los docentes/investigadores que conforman el claustro de profesores de la universidad son los generadores naturales de libros que serán publicados por esta. La función docente se complementa con la escritura de textos académicos, dicha actividad tiene características del quehacer universitario que se rige por lógicas propias. No obstante, en las últimas décadas se han revalorizado las redes académicas del conocimiento y fomentado la colaboración interinstitucional que debería comenzar a reflejarse también en los catálogos de las editoriales universitarias con la incorporación de autores de otras instituciones.

Las dificultades que enfrentan los editores de las universidades en la etapa de selección son diferentes a las de las editoriales comerciales (Piccolini, 2006); así, por ejemplo, los docentes/investigadores cumplen un doble rol con respecto a la producción académica y, tal como los define Torres Ripa, son “... los más significativos generadores de conocimiento al mismo tiempo que nos convertimos en sus más fieles consumidores" (Torres Ripa, 2007: p. 62).

Los docentes/investigadores conforman un colectivo con alta participación en el proceso editorial de las universidades. Por un lado, buscan publicar para dar a conocer su trabajo y, por otro, la mayoría, necesitan publicar por las exigencias de la evaluación profesional, lo que repercute directamente en la conformación del catálogo editorial. Por otra parte, los propios autores, en muchas ocasiones, contribuyen con el financiamiento de las ediciones usando subsidios de los proyectos de investigación, fondos de los departamentos donde desarrollan su actividad o consiguiendo patrocinadores.

Las editoriales universitarias tienen pocos autores externos a la institución lo que podría dar cuenta de una gestión endogámica de la actividad editora, aunque se fomente la colaboración académica con instituciones externas. Otros autores que suelen aparecer son los autores categorizados como clásicos, cuyas ediciones tienen la finalidad de proveer textos modélicos para fines académicos.

La autoría en las Humanidades y Ciencias Sociales se caracterizaba por ser individual, no obstante, este paradigma está cambiando hacia la autoría colectiva probablemente influenciado por las Ciencias Duras que imponen su modelo de equipos multidisciplinarios, la obligación de publicar (Silva, 2005) y el predominio de los artículos en revistas.

Por lo que se refiere a los temas que publica una editorial universitaria estos están en concordancia con las áreas en las que se especializa la institución y, frecuentemente, se hacen eco de las temáticas novedosas o de urgencia social, como así también la producción de literaturas locales y regionales que no encuentran espacio en editoriales comerciales. Los resultados de los estudios sobre las editoriales universitarias argentinas realizados a comienzos de la década del 2000 fueron contundentes en cuanto al predominio de las temáticas relacionadas con las Ciencias Sociales en detrimento de las Ciencias Duras. Esta tendencia se explicaría porque los libros de Humanidades y Ciencias Sociales no requieren una producción altamente técnica 
como lo demandan los de las Ciencias Duras por la complejidad de los gráficos e imágenes al momento de diseñar e imprimir (De Sagastizábal, 2002: 11).

Mientras tanto, los géneros discursivos que representan la creación del ámbito universitario "pertenecen al género académico (también denominado científico, científicoacadémico o especializado, en ocasiones con diferencias en su definición)" (Navarro y Brown, 2014: 75). Su caracterización está determinada, entre otros aspectos, por las áreas y disciplinas específicas que los generan y delimitarlos es un tema en discusión Uno de los criterios para ello es que "el discurso académico está constituido por el conjunto de textos producidos por la comunidad a través de medios científicos y académicos tales como publicaciones periódicas, libros especializados, conferencias en congresos de la disciplina, entre otros" (Navarro y Brown, 2014: 76).

También las colecciones y series son un elemento de la actividad editora que evidencia políticas, concepciones y relaciones propias de la editorial que las crea. Según Costa y Garone Gravier (2020: 1) "la colección editorial puede concebirse como una forma de compilación, una propuesta de ordenamiento de obras de diversa índole, las cuales se presentan relacionadas dentro de un conjunto asequible y coherente, integrado mediante la apelación a cierto denominador común." En las colecciones las obras se agrupan en base a criterios específicos: determinados géneros discursivos o literarios, recortes temporales, lenguas de traducción, temáticas definidas, formatos, el perfil de los lectores a los van dirigidas. La creación de colecciones y la integración de cada obra a cada una de ellas "constituye una estrategia editorial". En general, en el ámbito universitario los libros se agrupan en colecciones con mayor o menor grado de planificación y, a veces, con un desarrollo errático debido a contingencias institucionales más que al devenir del propio tema.

Según Genette, un texto se hace libro cuando el autor y editor definen con intencionalidad y responsabilidad un paratexto que oficia de umbral entre el interior del texto y la mirada externa a ese contenido. El paratexto tiene como función esencial ser un discurso auxiliar al servicio del texto, está formado por el peritexto y el epitexto. Se denomina peritexto a los elementos que se encuentran en "la obra alrededor del texto, en el espacio del volumen, como el título o prefacio y a veces inserto en los intersticios del texto, como los títulos de capítulos o ciertas notas" (Genette, 2001: 10). Por otra parte, el epitexto lo conforman todas las acciones por las que un texto puede hacerse conocido o llegar al público, como una entrevista al autor, reseñas periodísticas o en una comunicación más privada como las recomendaciones boca a boca. Estas manifestaciones ocurren fuera del libro: diarios, revistas, conferencias, coloquios. Y su circunstancia temporal puede ser anterior (proyecto de un autor), original (entrevista o reseña cuando se publica la obra) o tardía (conversaciones o coloquios) (Genette, 2001: 296). Esta instancia de la edición universitaria suele ser la más deficitaria, ya que se encuentran muchas dificultades para difundir y dar a conocer lo publicado.

Con respecto a la materialidad o soporte del libro editado por las universidades, en sus inicios, estas ediciones no se presentaban como un objeto atractivo, generalmente las cubiertas o tapas eran monocromas y sin ilustraciones. Sin embargo, en los últimos tiempos estos libros han incorporado el diseño gráfico en los paratextos editoriales, resultando ediciones mucho más atractivas (Pérez Lasheras, 2007: 42).

Es importante destacar que las ediciones universitarias tienen como prioridad obtener un texto de excelencia, por ello cuidan las erratas, incluyen abundantes citas bibliográficas, incorporan extensas notas al pie, usan la terminología especializada y generalmente resultan libros extensos. Se busca lograr un objeto digno y económicamente accesible. 
Por último, las editoriales universitarias suelen realizar co-ediciones con otras instituciones nacionales o internacionales que tienen similares características, con el objetivo de afianzar la cooperación para optimizar los recursos y expandir su proyección hacia otros ámbitos (López Valdés, 2006).

Es pertinente, aunque el tema excede el marco de esta investigación, señalar que la edición electrónica rompe con esta materialidad y le suma una impronta donde se altera el orden de los discursos y se desdibuja el objeto material, el que adquiere las formas del aparato electrónico y su mayor fragmentación presentando los textos en una continuidad construida por el propio lector, quien decide y clasifica la coherencia de la totalidad del texto.

\section{Las publicaciones de la Facultad de Filosofía y Letras de la UBA}

Desde el momento de su fundación en 1896 la Facultad de Filosofía y Letras de la UBA tuvo un papel protagónico como editora de sus propias publicaciones. Las primeras estuvieron vinculadas al funcionamiento, gestión de la nueva casa de estudios y material para la enseñanza. Abundan los reglamentos, los planes de estudios y textos para la enseñanza de las distintas materias que se dictaban en la Facultad.

La Dirección de Publicaciones se establece en 1915 y con su producción se abocó a la consolidación del pensamiento nacional. Planificó y publicó importantes colecciones de documentos de la Historia Argentina aportando fuentes para su estudio, y diseñó varias colecciones destinadas a publicar las obras literarias nacionales pioneras en sus diferentes géneros como novelas, obras de teatro, poesía y ensayos.

2. Casa Editora Coni, Peuser, Compañía Sudamericana de Billetes, Institución Cultural Argentina, A. López, Talleres Gráficos del Ministerio de Agricultura, Imprenta de J. A. Alsina, Imprenta de M. Biedma, Imprenta A. Cantiello, J. Roldán, A. Echepareborda, G. Kraft, Imprenta del Congreso de la Nación, entre otras.
Hasta la década de 1950 las impresiones se realizaban en imprentas externas ${ }^{2}$ a la Facultad, o se recurría a la de la Universidad de Buenos Aires que desde 1923 tenía su propia imprenta. La Facultad funda su propio taller de impresión en 1957 y en 1961 se crea la Oficina de Publicaciones de la Facultad de Filosofía y Letras (OPFyL). Esta oficina se ocupaba fundamentalmente de la distribución y venta de publicaciones. Las resoluciones hechas para ordenar los trámites de este sector, en general, involucran al jefe del taller de la imprenta, a la división de venta de las publicaciones y a la Biblioteca Central como coordinadora del canje de las publicaciones y receptora de ejemplares en depósito con el objeto de formar la colección de las publicaciones de la Facultad.

La Resolución No. 991 y la 1023 de 1973 implementan el procedimiento de edición, distribución y venta de las publicaciones. Se detallan los miembros de la Facultad que podían requerir publicaciones (docentes y directores de Instituto) y cómo debían hacerlo. Se dan detalles de los paratextos que tenían que figurar en los libros y los ejemplares que se debían imprimir según lo que informaba la oficina de venta y lo que requería el canje que gestionaba la Biblioteca Central, e incluía los requisitos de propiedad intelectual y de la ley 11.723. La Biblioteca tenía la obligación de publicar un catálogo anual y alertar cuando la edición se reducía al 10\% del tiraje. Esta normativa pierde vigencia cuando en diciembre de 1979 se aprueba la Resolución No. 1052 que implanta un nuevo Reglamento de publicaciones. El área estaba a cargo de la Secretaría de Prensa y Publicaciones que recibía los pedidos de impresión que debía aprobar el Decanato o la Secretaría Académica.

En 1990 el Consejo Directivo aprueba la Resolución No. 2562/90 con el fin de otorgar un marco normativo de la Pro Secretaría de Publicaciones para la planificación, producción y gestión editorial en plena articulación con las políticas científicas vigentes. Lo particular de este reglamento es la conformación por primera vez del Consejo 
Editor como instancia responsable de la planificación de la política editorial; este cuerpo asesor estaría integrado por el decano y 5 miembros de reconocida trayectoria -debía incluir, al menos, un docente y un estudiante con el 50\% de las materias aprobadas - mostrando una apertura democrática en la toma de decisiones institucionales. Las funciones quedaban enmarcadas en planificar, evaluar las publicaciones, recomendar su publicación, convocar evaluadores externos si fuera necesario, fijar el orden de publicación del material en función de los recursos y, de acuerdo con las políticas editoriales, recomendar la realización de co-ediciones con cualquier institución nacional o extranjera, pública o privada.

Esta normativa fue dejada sin efecto por la Resolución (CD) No. 880/06 del año 2006, la que incorpora modificaciones y suma artículos en busca de abarcar la complejidad que implica administrar la Subsecretaría de Publicaciones. Cambia la composición del Consejo Editor, pasó a estar integrado por 7 miembros; lo novedoso de esta ampliación es la incorporación de un representante del claustro nodocente y la elección de 4 suplentes que aseguren la representatividad de los 4 claustros del gobierno universitario. El apartado "De las publicaciones" incluye especificaciones para cada tipo de publicación y dictamina la obligación de que cuenten con una evaluación externa que garantice su calidad académica. Además, la propia Subsecretaría de Publicaciones queda habilitada para avalar propuestas al igual que las Secretarías, los Institutos, los Departamentos y el Decanato reconociendo una profesionalización del área editorial.

Este reglamento estuvo vigente hasta el año 2015 cuando es modificado por la Resolución CD No. 1773/15, con el fundamento de "adecuarlo al carácter cambiante de las publicaciones en sus diversos soportes, y corregir la rápida obsolescencia de algunas de sus disposiciones".

Es posible suponer que los diferentes reglamentos y, sobre todo, las modificaciones introducidas en los tres últimos, muestran el interés institucional por sostener la producción editorial bajo normativas acordes a las demandas organizativas de la Facultad, en articulación con los estándares internacionales en constante cambio y actualización ante el impacto de las nuevas tecnologías y las políticas científicas derivadas de ellas.

\section{Metodología}

En este artículo nos proponemos mostrar resultados que contribuyan a conformar la Historia de la Cultura Impresa en la Facultad de Filosofía y Letras de la Universidad de Buenos Aires en el marco del Proyecto Filo:CyT. Nuestro principal objetivo ha sido identificar tendencias, hitos y cambios del catálogo editorial de libros en las décadas comprendidas desde el retorno a la democracia en 1983 en la Argentina.

Para acercarnos a este objetivo nos propusimos:

» Identificar la producción editorial monográfica de las décadas de 1990 y de 2010.

»Analizar esta producción editorial desde la creación intelectual y desde la materialidad.

»Estudiar la difusión y la circulación de las publicaciones.

Se aplicarán para ello métodos cuantitativos que permitan conocer la producción editorial de la Facultad y se analizarán e interpretarán los resultados obtenidos con el fin de relatar una historia local de la cultura impresa. En las Humanidades y Ciencias Sociales el desarrollo de la argumentación de investigaciones fundadas en datos cuantitativos e interpretativos permite, con datos concretos, aproximar una respuesta a la problemática planteada desde una mirada general. 
El catálogo editorial de la Facultad de Filosofía y Letras de la UBA hoy cuenta con casi 1.500 títulos. En este artículo se analizaron los libros de las décadas de 1990 (230 libros) y de 2010 ( 284 libros). La primera de ellas es una década en donde se reflejan los cambios generados en las políticas editoriales a partir del retorno de la democracia en 1983 y, la segunda, por considerar que da cuenta de los cambios tecnológicos iniciados en la década precedente. El trabajo se realizó en el contexto de la pandemia de Covid-19 que dificultó, en algunas ocasiones, la verificación de datos necesarios para realizar el análisis.

Las tres perspectivas de análisis de la producción son la creación intelectual, la materialidad y la difusión-circulación y cada una de ellas agrupan diferentes variables definidas (o generadas) para los fines de esta investigación.

\section{Perspectiva de Creación intelectual}

Dentro de la Creación intelectual se incluyeron aquellas variables que tienen relación con la autoría y el contenido temático de los libros. En la edición universitaria el autor se revela como un concepto de una gran complejidad que depende de un contexto específico para ser asumido y puede ser analizado desde múltiples abordajes (Premat, 2006), como ser: la relación del autor o autores con las obras, con el contexto académico universitario, con otros autores, etc.

Se denomina "Monoautoría" al tipo de autoría en la que las obras están a cargo de una sola persona. En lo que respecta a la colaboración entre autores existen principalmente dos tipos: la contribución separada e individual (obra en colaboración) y aquella en la que las aportaciones de los coautores se funden en un todo indiscernible (obra colectiva) (Martínez de Sousa, 2004: 77). En este último caso, denominado "Multiautoría" son textos escritos por varias personas sin identificar qué partes realizaron individualmente; en cambio hablamos de "Autoría colaborativa" si la creación corresponde a varias personas y se puede identificar la participación individual de cada una de ellas.

Para analizar la autoría desde la relación de los autores con la obra se identificaron, dentro de la Autoría colaborativa, algunas modalidades particulares tales como los compiladores; los compiladores que no participaron como autores en la obra que coordinaron; traductores y "autores clásicos" como actores propios de una Facultad de Humanidades y sus ediciones anotadas y críticas; los dibujantes, y otros tipos de colaboraciones como fotógrafos y asistentes.

La tercera aproximación a la autoría, que aborda la relación del autor con el contexto académico universitario, permitió considerar dos variables más: la identificación de autores ausentes en el catálogo, y la pertenencia institucional. Por autores ausentes entendemos a aquellos docentes/investigadores destacados, dentro y fuera de la institución, con conocida producción académica pero que no publican en el sello editorial de la Facultad por desconocimiento o no encontrar atractiva la opción de publicar allí. La variable de pertenencia institucional tiene como finalidad detectar la presencia de autores externos a la Institución para determinar el nivel de colaboración interinstitucional en el catálogo.

Si bien otros abordajes de la autoría en relación con el contexto académico y social permitirían observar diversas características de la producción editorial en estudio tales como la participación de los estudiantes, la incidencia de mujeres como autoras, editoras, directoras; la producción de participantes en cursos y actividades de extensión, etc., a los efectos de los objetivos propuestos, exceden los alcances y posibilidades de este artículo. 
La perspectiva de creación intelectual también comprende la variable que analiza las áreas temáticas que tienen representación en el catálogo. Para ello se definieron 27 materias que responden, fundamentalmente, a las especializaciones de los distintos Institutos de investigación, es por ello que Literatura e Historia, entre otros, están subdivididas en varios temas (Literatura Argentina, Historia Oriental, etc.). Se sumaron algunas áreas generales que se estudian en las carreras de grado y un área que agrupa publicaciones con información institucional.

Para estudiar las prácticas discursivas de los títulos y, a los fines de esta investigación, hemos definido dos variables, una que presenta el libro desde un lenguaje académico o científico, y la otra que apela a un lenguaje metafórico o literario que denominamos "títulos sugestivos", con un objetivo más convocante. El uso de alguno de estos tipos de títulos, puede determinar la inclusión de un subtítulo a fin de mediar ante el lector para informar de qué trata el libro. Se analizará también el uso de subtítulos para ampliar la información del contenido y la forma de unir el título y el subtítulo en estos paratextos.

Completan esta perspectiva los géneros discursivos de los textos, y se buscará conocer aquellos que se sumen a los típicos de una editorial universitaria. Entendemos por textos académicos aquellos propios de una universidad que reflejan el quehacer de los docentes cuando escriben textos para la enseñanza o para el debate, que desarrollan opiniones a modo de ensayo o ficha de cátedra. En cambio, consideramos textos científicos, aquellos que mencionan explícitamente la pertenencia a un proyecto de investigación subsidiado. A estos dos grupos se suman las actas de congresos; los textos conmemorativos dedicados a personalidades destacadas o aniversarios institucionales; las ediciones críticas que toman textos de autores clásicos y le suman notas y análisis con valiosos estudios preliminares; bibliografías que se compilan sobre un tema o autor; textos literarios producto de la creación de un autor o grupo de autores (como la producción literaria de un taller); textos epistolares que reproducen la correspondencia de autores; textos dedicados a niños a fin de llegar específicamente a ese público; o textos en historieta como ejemplo de un discurso que también se manifiesta en el ámbito académico.

\section{Perspectiva de materialidad}

Esta perspectiva agrupa variables tales como las series o colecciones y los diferentes aspectos del soporte físico de los libros.

Una primera variable, buscará identificar y analizar estrategias que agrupan las obras en colecciones. La injerencia y autonomía de los diferentes Institutos de Investigación en la creación y el diseño de colecciones es una característica de los procesos propios de la Institución en estudio. Estas colecciones tienen un mayor o menor grado de planificación y, a veces, un desarrollo errático debido a contingencias institucionales más que al devenir del tema que abarcan.

Por lo tanto, se hará un reconocimiento general en busca de denominadores comunes o criterios para la agrupación de textos en colecciones y series especializadas y en colecciones generales que apelan a la suma de publicaciones cuya matriz suele estar determinada por la propia Pro o Subsecretaría de Publicaciones ${ }^{3}$, o por el Instituto que gestionó la publicación o por una disciplina en particular, sin contar con un objetivo explícito de unificación del corpus. Estas características se confrontarán con un análisis cuantitativo que mida la cantidad de series y la productividad de cada una de ellas con el fin de observar la profesionalización del área.
3. Se denominó Pro Secretaría desde 1990 hasta el año 2006 en el que cambia su nombre a Subsecretaría. 
Otra variable de la materialidad es el análisis de la representación del sello editorial que busca identificar los componentes que lo conforman, tales como el uso del logo de la Universidad, nombre del Instituto, nombre de la Editorial y las menciones a entidades partícipes de co-ediciones, ya sean instituciones públicas o privadas.

También se tendrá en cuenta el soporte del objeto físico, ya sea este impreso con versión digital, o sea puramente digital, y se buscará obtener la media de páginas para identificar cambios en la extensión de los libros.

Por último, se hará una aproximación al diseño de las tapas y cubiertas como un elemento distintivo de la colección editorial. A los fines de este análisis se pudieron diferenciar de manera general 4 tipologías que representan el universo estudiado: las tapas textuales, las que apelan al diseño gráfico para jerarquizar la información, las que incluyen dibujos y las que incluyen fotos.

\section{Perspectiva Difusión-Circulación}

En esta perspectiva se estudiarán una serie de epitextos que permitan conocer la difusión de los libros publicados por la Facultad. En esta primera aproximación se analizarán los libros de la década de 2010 para observar cómo se fueron divulgando en ámbitos internos y externos a la institución y también determinar su circulación en otros espacios. Con esta finalidad se definieron las siguientes variables que mediante múltiples búsquedas se fueron relevando: reseñas en revistas de extensión de la Facultad; reseñas en revistas académicas propias y externas; anuncios en diarios y agencias de noticias; presentaciones en los espacios físicos de la institución o en otras instituciones; entrevistas a los autores; difusión digital en canales propios y en canales externos (Twitter, Facebook, blog, sitios web, etc.). En lo que se refiere a la circulación de los textos en otros espacios, durante las búsquedas realizadas, se identificaron dos circuitos cuya observación se considera relevante. El primero es el catálogo bibliográfico colectivo WorldCat que reúne más de 500 millones de registros de colecciones de bibliotecas de todo el mundo; se buscarán en él los libros de estas dos décadas para constatar la visibilidad que tienen allí.

El segundo circuito identificado es el de los programas de estudio de materias, seminarios, cursos, etc., en los que se observó la presencia de libros producidos en la Facultad y que en un estudio futuro más detallado aportará otros datos para analizar e interpretar.

\section{Resultados y discusión}

El primer dato relevante que surge de la comparación de las dos décadas analizadas es que hay una diferencia de 54 libros entre ambas, siendo 230 en la década 1990 y 284 en la de 2010, el análisis de las variables se hizo siempre teniendo en cuenta estos universos.

Cuando abordamos la autoría, se aprecia claramente un descenso en la década de 2010 de las obras hechas por un solo autor (monoautoría), con una disminución de un $25 \%$ con respecto a la década de 1990 (Gráfico 1). En cambio, cuando observamos la autoría colaborativa, esta se incrementó en más de un $25 \%$ en la década de 2010 ; este dato coincide con la dinámica de trabajo en equipo que se va trasladando a las Humanidades y Ciencias Sociales desde las Ciencias Exactas. 
80

70

60

50

40

30

20

10

0

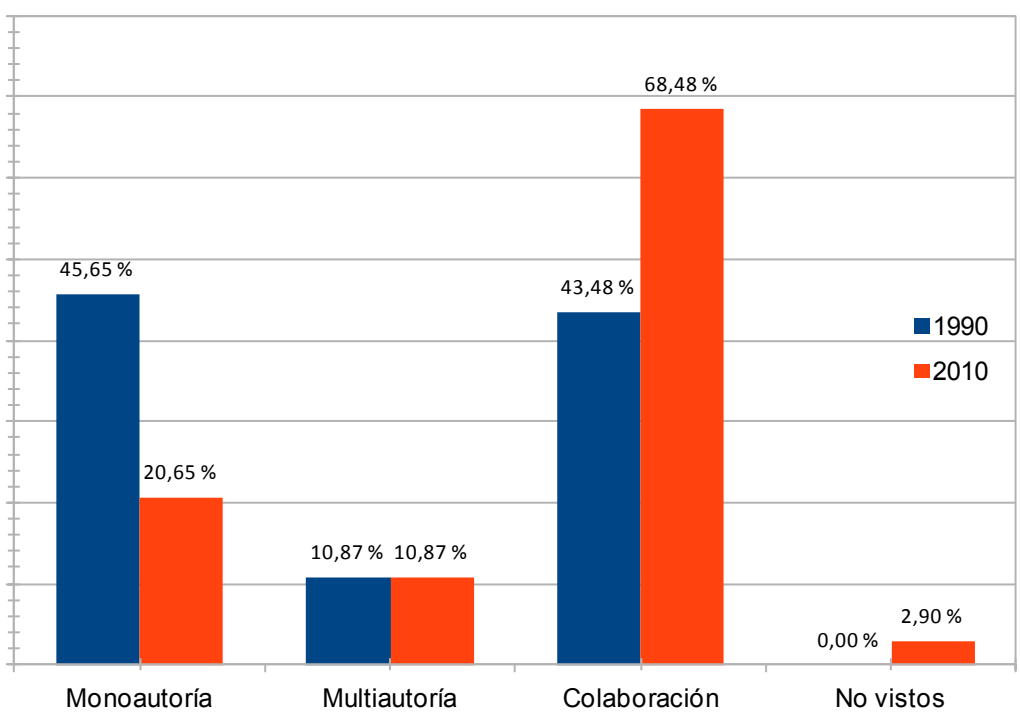

Fuente: elaboración propia
Gráfico 1. Distribución por tipo de autoría (Décadas 1990-2010)

La multiautoría se mantiene baja en ambos periodos ( $1990 \mathrm{n}=25$ y $2010 \mathrm{n}=30$ ). Los autores de la década de 2010 ( $n=133)$ superan a los de la década de 1990 ( $n=89)$ y se corresponde con el aumento de obras en multiautoría.

La autoría colaborativa (Gráfico 2) requirió un tipo de análisis más minucioso debido a los diferentes perfiles de autor que intervienen en estas obras, en las que, por ejemplo, los traductores tienen una relevancia particular dado el perfil de la institución que nos ocupa. La característica general, en este subconjunto, es el aumento de todos los tipos de autoría en la década de 2010; este hecho tiene relación con el aumento de un $25 \%$ de la autoría colaborativa visto en el análisis del tipo de autoría, como se mostró en el gráfico 1.

Todos los datos son significativos. Por un lado, las marcadas diferencias en el número de autores, compiladores y otro tipo de autoría (pequeñas colaboraciones, institucional, fotógrafos, curadores) entre una década y otra. Por otro lado, los traductores y los autores clásicos, que tienen que ver con los estudios críticos de obras clásicas de las Humanidades, se mantienen presentes y se incrementan.

La presencia de dibujantes refleja la elección de publicar historietas por parte de la Editorial de Filo como nuevo lenguaje popular usado en un ámbito académico en su objetivo de divulgación. También se encontró solo un libro Para niños en la década de 2010 mientras que, en la anterior, se publicaron 3 títulos.

Finalmente, están los compiladores que no participan con colaboraciones dentro del texto que coordinan; en 2010 se registran más comportamientos de este tipo que en la década de 1990, aunque respecto del número de autores en ambos periodos la diferencia pierde relevancia.

La pertenencia institucional es una de las variables más complejas de analizar y exige de una investigación de otras características. En esta oportunidad las diferencias entre las dos décadas no son muy grandes. Hay un descenso del número de autores externos (1990: $10 \%$ y 2010: 5\%), un incremento de las obras de autoría mixta (1990: 42,79\% y 2010: 50\%) y la autoría de Filo se mantuvo prácticamente igual (1990: 47\% y 2010: $46 \%$ ). Esto puede ser un indicio de los cambios que se producen en base a los nuevos 


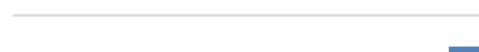

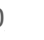

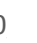
0 0

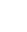
10

\begin{tabular}{|c|c|c|}
\hline & Compiladores & $\begin{array}{c}\text { Comp-no } \\
\text { autor }\end{array}$ \\
\hline $\mathbf{1 9 9 0}$ & $8,32 \%$ & $0,73 \%$ \\
\hline $\mathbf{2 0 1 0}$ & $11,52 \%$ & $2,12 \%$ \\
\hline
\end{tabular}

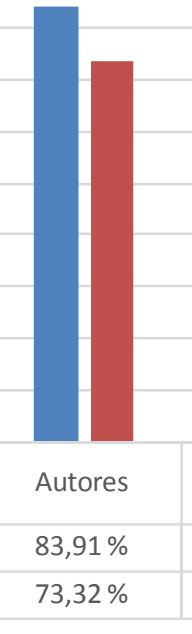

\begin{tabular}{|c|c|c|c|}
\hline & \multicolumn{3}{c}{-} \\
\hline Traductores & Clásicos & Dibujantes & Otros autores \\
\hline $3,75 \%$ & $1,55 \%$ & $0,27 \%$ & $1,46 \%$ \\
\hline $2,32 \%$ & $1,11 \%$ & $0,17 \%$ & $9,44 \%$ \\
\hline
\end{tabular}

Fuente: elaboración propia

Gráfico 2. Distribución de las autorías colaborativas (Décadas 1990-2010)
Nota de alcance: este gráfico es meramente ilustrativo del comportamiento de los autores colaborativos y los números son estimativos ya que no se conformó una base de datos depurada para su análisis a efectos de subsanar el solapamiento u otras inconsistencias.

paradigmas del trabajo de investigación donde la colaboración interinstitucional es muy valorada en las instancias de evaluación académica como forma de contrarrestar la endogamia propia de las instituciones.

Con la intención de identificar cual era el comportamiento de los autores ausentes en el catálogo, se conformó un universo con los directores de Institutos y decanos que se desempeñaron a lo largo de los últimos 30 años y tuvieron una reconocida trayectoria y trascendencia. Este universo quedó conformado por 69 autores, de los que casi un $67 \%$ publicaron al menos un libro en las décadas estudiadas y, además, se pudo observar que tuvieron una producción promedio de 3 libros dentro del catálogo de Filo.

Por lo tanto, los autores ausentes y sin ninguna presencia en el catálogo de la editorial llegan al 33\%; en una primera aproximación se encontró que una minoría de ellos tienen muchos libros publicados en editoriales comerciales o de otras instituciones académicas; en cambio, los restantes han publicado entre 1 y 3 libros lo que, aparentemente, coincidiría con la tendencia del grupo que publicó en la Facultad. Por ahora, consideramos de interés mostrar estos datos, a pesar que aún son preliminares para poder inferir alguna otra conclusión.

Para el estudio de las áreas temáticas que aborda el Catálogo editorial de Filo los diferentes temas se agruparon en 27 materias que responden, fundamentalmente, a las especializaciones de los distintos institutos de investigación; además, se sumaron algunas de las áreas generales que se estudian en las carreras de grado y un grupo de publicaciones que tienen información institucional. El Gráfico 3 permite analizar el comportamiento de los temas en las dos décadas estudiadas. 


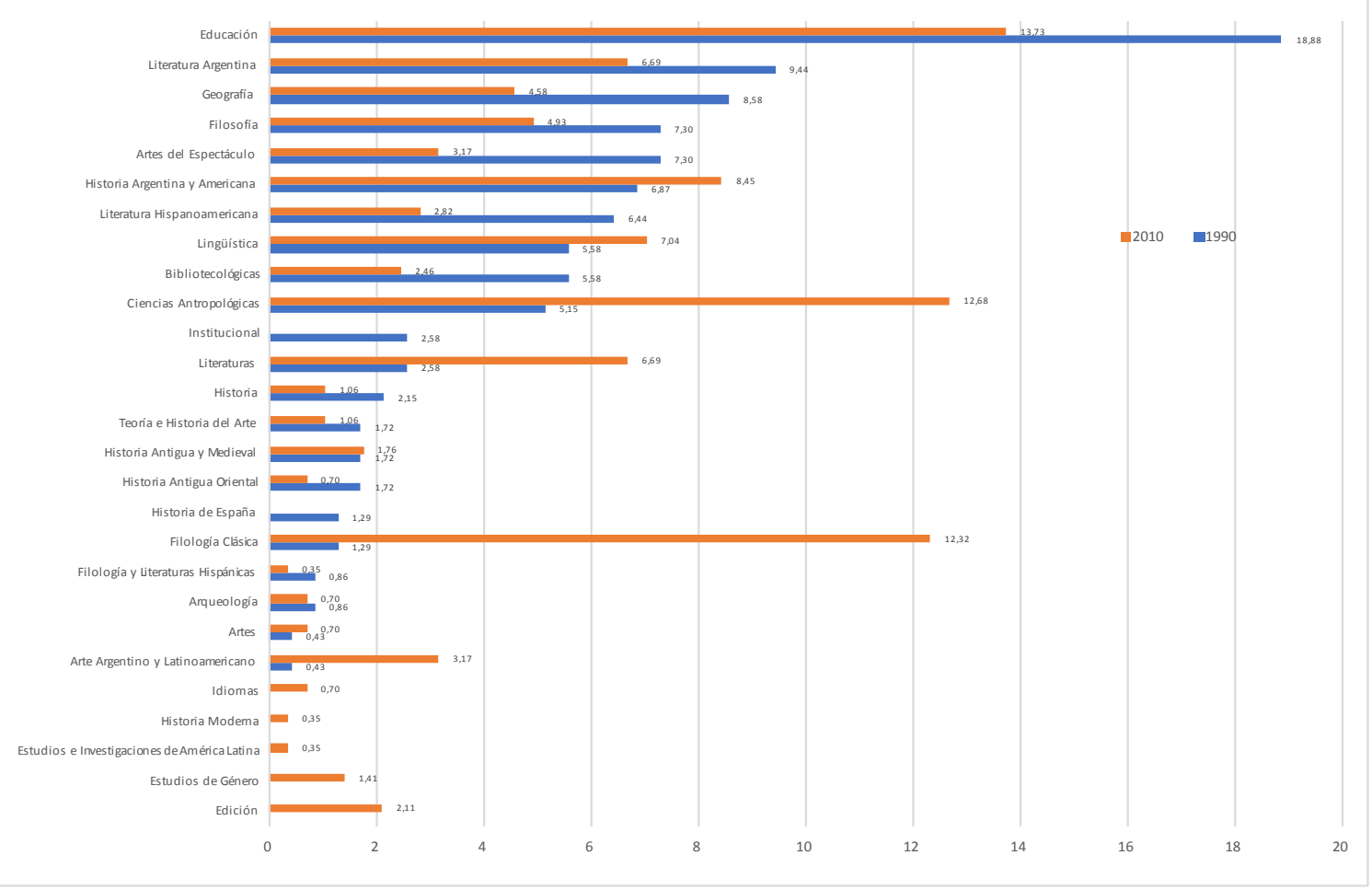

Fuente: elaboración propia

Gráfico 3. Distribución de la producción por temas (Décadas 1990-2010)

En líneas generales se puede observar que la distribución está representada por unas pocas disciplinas, 1 a 3 , que superan la concentración del $10 \%$, un grupo de 5 a 9 áreas con una presencia del $4 \%$ a un $9 \%$ y el resto de las materias presentan una baja productividad indicada con el $1 \%$ y $2 \%$.

Destacan Educación y Ciencias Antropológicas como las áreas con mayor cantidad de libros en las décadas estudiadas, y se observa que Educación disminuyó un $5 \%$ en la década de 2010. También resalta Filología Clásica con un incremento del $11 \%$ en la década del 2010, si bien es necesario profundizar las razones de este cambio; se constató que la serie Textos y Estudios del Instituto de Filología Clásica en la década de 2010 concentra la mayor cantidad de entregas con publicaciones de investigaciones, ediciones y traducciones.

Un subgrupo con áreas de una mayor producción como Historia Argentina y Americana, Lingüística y Literatura aumentaron unos puntos del porcentaje en la década de 2010 con respecto a la de 1990. En cambio, otro subgrupo pierde unos puntos del porcentaje de representación tales como Literatura Argentina, Geografía, Filosofía, Artes del Espectáculo, Literatura Hispanoamericana, Bibliotecología. Entre los múltiples factores que podrían explicar este cambio, uno de ellos puede ser la preferencia por publicar en revistas académicas en lugar de libros, o que la propia disciplina haya consolidado una periódica, como es el caso de Bibliotecología y la revista Información, cultura y sociedad.

Finalmente, tenemos un grupo menor que aparece solo en la década de 2010 ya sea por la creación de una nueva carrera como es el Departamento de Edición, o de institutos tales como el Instituto de Investigaciones de Estudios de Género (IIGE) y el Instituto 


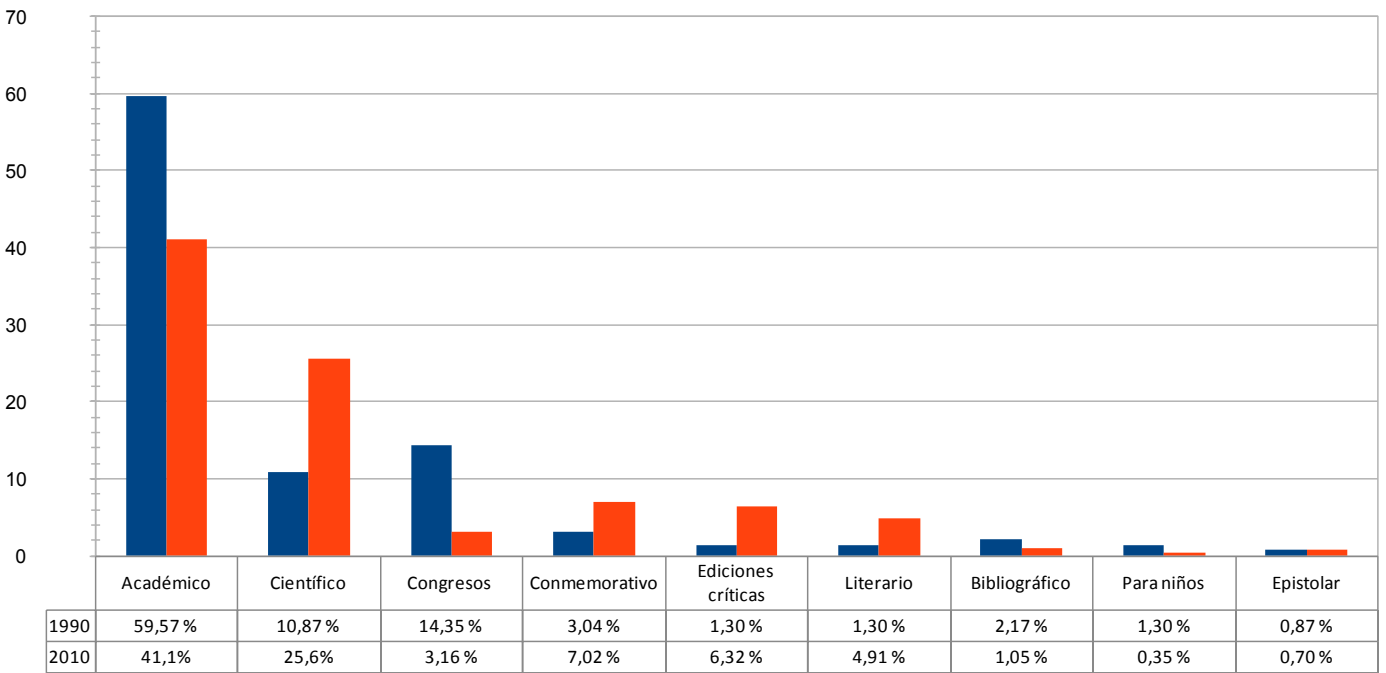

Fuente: elaboración propia

Gráfico 4. Distribución de la producción por género discursivo (Décadas 1990-2010)

Interdisciplinario de Estudios e Investigaciones de América Latina (INDEAL). Por el contrario, solo dos áreas tienen publicaciones únicamente en la década de 1990 (Historia de España) y textos con información institucional. Estos últimos son textos con memorias, reglamentos, guías de trámites, programas, entre otros, y se observó que siempre tuvieron algún tipo de presencia a lo largo de más de los 100 años del catálogo. La ausencia en la década de 2010 podría estar indicando que esta información circula y se publica en las diferentes plataformas y páginas de la Facultad.

Si bien el gráfico refleja que algunas disciplinas son más fuertes que otras al momento de conformar el catálogo editorial de esta Facultad, también muestra la permanencia de las más débiles en esta ruta de publicaciones.

Los géneros discursivos que se encuentran en las décadas analizadas responden cabalmente a lo que se espera encontrar en el catálogo de una editorial universitaria. El análisis mostró que las publicaciones se concentran en 3 tipos específicos: los textos académicos, los textos científicos productos de investigaciones, y los congresos. Completan el panorama los textos conmemorativos, las ediciones críticas, textos literarios, bibliografías, entre otros.

Se destacan cuatro situaciones: tipos de texto que se mantiene en niveles altos en las dos décadas como son los académicos (1990: 59,57\% y 2010: 41,10\%); tipos de texto de los que se invirtió su tendencia de una década a otra como los congresos (1990: $14,35 \%$ y $2010: 3,16 \%$ ) y las ediciones críticas (1990: $1,30 \%$ y $2010: 6,32 \%$ ). Por otra parte, hay algunos tipos de texto que dejaron de aparecer de una década a otra y otros que surgieron en el periodo más reciente; en el primer caso se encuentran los informes, los directorios y las actas y en el segundo los libros para niños, los de idiomas en lenguas originarias y las historietas (Gráfico 4).

Si bien los textos académicos predominan en ambos períodos, disminuyen un $19 \%$ en la década de 2010; esto tal vez tenga una correlación con el aumento del 15\% de los textos científicos que publican los resultados de las investigaciones en estrecha relación con la institucionalización y exigencias de los proyectos de investigación subsidiados. 


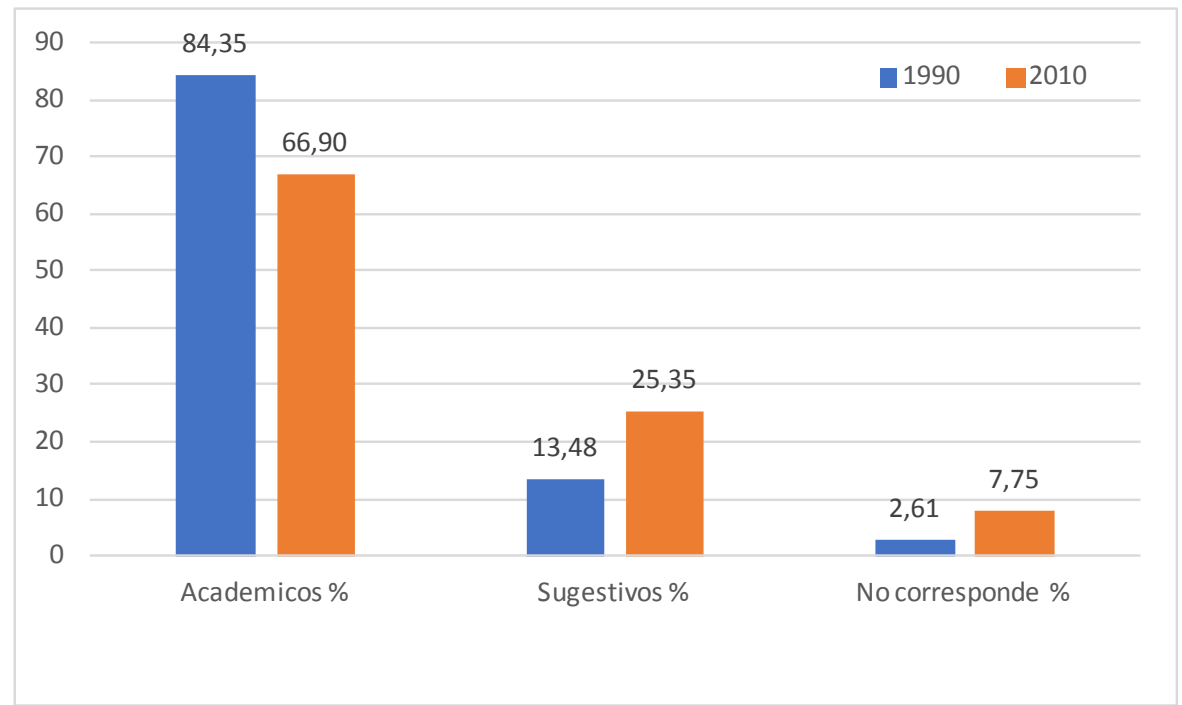

Fuente: elaboración propia

La lectura de los títulos nos llevó a definir dos tipos: los "títulos académicos" como aquellos que usan un lenguaje formal, científico y describen claramente el tema que aborda el libro. Y, por otro lado, están aquellos que consideramos "títulos sugestivos" como los que apelan a un lenguaje metafórico, literario o provocador que deja la libre interpretación del lector para comprender la temática del interior del libro (Figura 1).

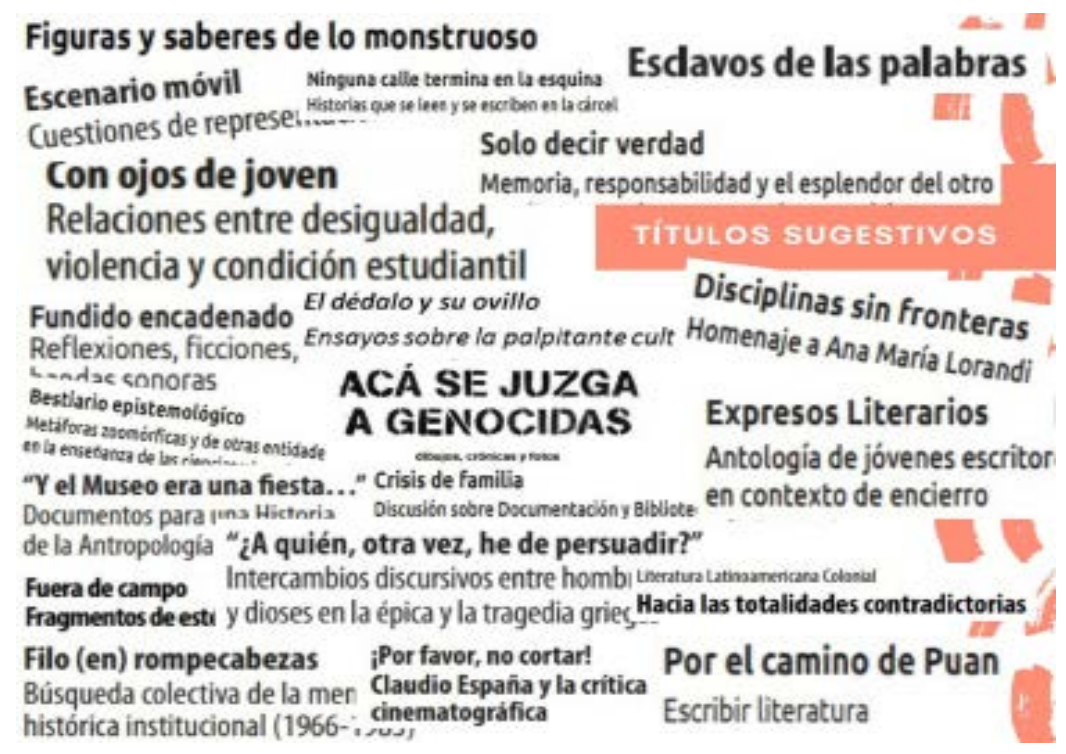

El Gráfico 5 muestra el incremento de los títulos sugestivos en la década de 2010, si bien predomina el discurso académico al momento de colocar los títulos en concordancia con el perfil de la institución editora, aparecen títulos con otro lenguaje más convocante y atractivo con el fin de llegar a otros públicos o interpelar al lector.

Los títulos que corresponden a obras literarias o textos clásicos no se consideraron ya que no representan una intencionalidad de los autores o editores de esta editorial
Gráfico 5. Distribución por tipo de títulos (Décadas 1990-2010)
Figura 1. Algunos títulos sugestivos 
Gráfico 6. Distribución de los subtítulos

(Décadas 1990-2010)

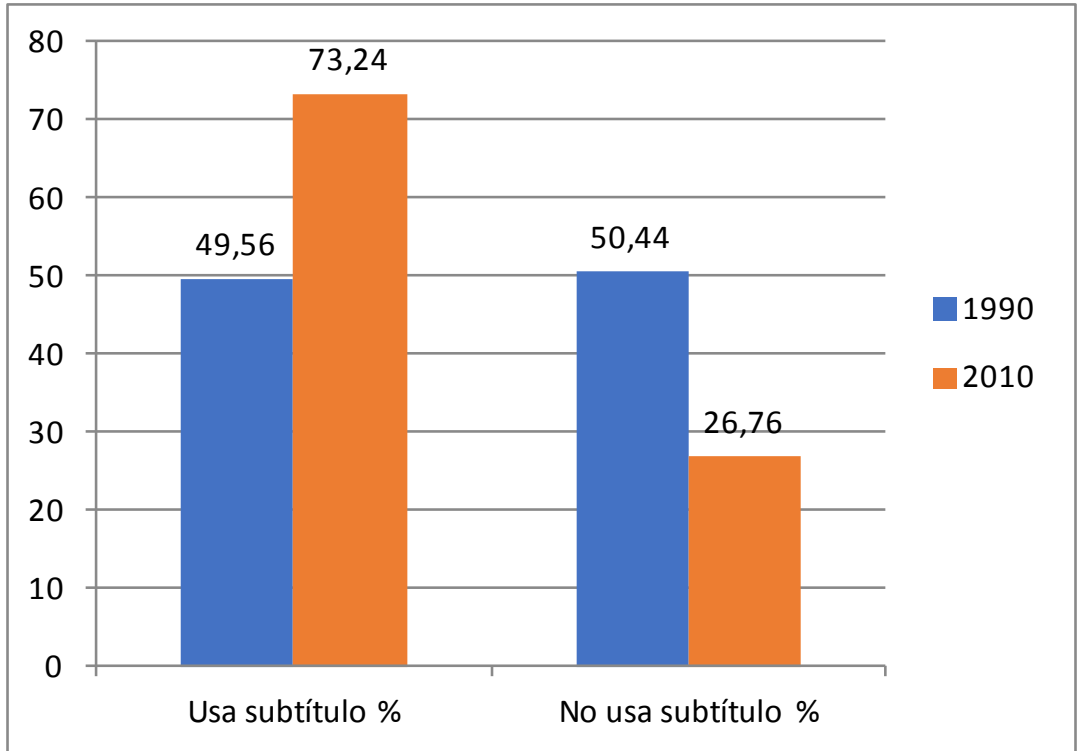

Fuente: elaboración propia

universitaria. Otro elemento que resulta interesante destacar es la inclusión o no de subtítulos como un componente textual de ayuda e intermediación entre el lector y el libro. El Gráfico 6 muestra un cambio de conducta en cuanto a los subtítulos; en la década de 2010 su uso se incrementa en casi un $24 \%$, una parte de este incremento lo puede explicar el aumento de los títulos sugestivos (aumentaron alrededor de un $12 \%$ ) que hacen necesaria la inclusión de un subtítulo para orientar al lector de lo que trata el libro. Otra parte lo puede explicar la necesidad de hacer las ediciones más atractivas con títulos breves que faciliten una aproximación rápida al texto, lo que hace necesaria la inclusión de subtítulos.

En las ediciones es habitual usar los dos puntos como el elemento vinculante entre el título y el subtítulo; partimos de la hipótesis que este signo gráfico se está reemplazando por el diseño tipográfico de las tapas, cubiertas y portadas de los libros donde la diferenciación de títulos y subtítulos se hace mediante el cambio de tipografía, tamaño de la tipografía o color de la impresión del texto. Sin embargo, las dos décadas estudiadas mantienen un valor cercano al $20 \%$ en el uso de los dos puntos como separador de título y subtítulos en sus paratextos impresos.

Por otra parte, tomando como inspirador el texto de Darnton (2010), analizamos si los títulos de las ediciones de la Facultad apelaban a la aliteración. Consideramos "aliteración" en un título cuando se repite una o varias palabras en la construcción del mismo con fines expresivos. Se identificó una baja representación de esta variable en las décadas estudiadas, aproximadamente un 6\% en la década de 1990 y menos de un $3 \%$ en la década de 2010. Algunos de esos títulos son: Análisis del discurso, disciplina interpretativa en interdisciplinariedad; Cuentos, cuentas, cuentes: relatos argentinos de género; Fronteras en perspectiva, perspectivas sobre las fronteras.

El análisis de los títulos en estas décadas muestra un panorama bastante homogéneo, donde continúa primando el discurso académico en consonancia con una Facultad de Humanidades y Ciencias Sociales; los cambios que se identificaron son sutiles, seguramente sea debido a la cercanía de las décadas y ambas están influenciadas por la profesionalización de las ediciones universitarias. 
Con respecto a la materialidad, en primera instancia abordamos las colecciones. Durante el desarrollo de este proyecto pudimos observar que el tamaño y complejidad del tema colecciones en la facultad y sus tramas y devenires ameritaría un proyecto aparte; por lo tanto, el análisis no se agotará en este artículo.

En primer término, pudimos observar que forman parte de colecciones o series bibliográficas diseñadas por la Pro o Subsecretaría de Publicaciones o por los Institutos el $78,26 \%$ de los libros publicados en la década de 1990 , y el $83 \%$ en la de 2010 lo que indicaría la existencia de una estrategia editorial para la producción. Solo hay 3 textos que tienen la colección del co-editor. Se pudo detectar colecciones que se mantuvieron a lo largo de los años, incluso algunas aumentaron su producción como Textos y Estudios; otras lo mantuvieron como Cuadernos de Bibliotecología y Cuadernos de Territorio y otras lo disminuyeron como Hipótesis y discusiones; esto último posiblemente como producto de la creación, en los últimos años, de nuevas colecciones de la Subsecretaría de Publicaciones.

De las 52 colecciones de la década de 1990 solo 6 publicaron entregas en la década de 2010, lo que muestra un cambio importante en su gestión. Además, 21 de ellas solo tuvieron un título o una entrega mostrando una proliferación de colecciones que no pudieron sostenerse en el tiempo y dispersaron la producción.

En cambio, en la década 2010 se identificaron 22 colecciones -30 menos que en la década de 1990-, de las cuales 16 se iniciaron a comienzo de siglo. Cuatro colecciones - Colección Saberes, Libros de Cátedra, Libros de Filo y Colección Puentes- concentran un $64 \%$ de la producción de la década, mostrando una clara decisión editorial de contrarrestar la dispersión de las décadas anteriores y, de este modo, consolidar colecciones que den identidad a la producción de la Facultad.

Por otra parte, se pudieron identificar colecciones y series especializadas que compilan textos agrupados en torno a un eje común. Y, por otro lado, también existen las generales que apelan a la suma de publicaciones cuyo eje suele estar determinado por el Instituto que la gestionó o por una disciplina en particular, sin contar con una intencionalidad explícita que le de unidad. En líneas generales, en la década de 1990 prevalecen las colecciones de los Institutos que se caracterizan por reunir la producción de sus investigadores siendo este el eje que agrupa las entregas.

En cambio, en la década de 2010, si bien mantienen vigencia algunas diagramadas por los Institutos, predominan las colecciones gestionadas por la Subsecretaría de Publicaciones que agrupa las ediciones en 4 ejes: la colección Libros de cátedra (53) responde a las necesidades de la enseñanza y contiene textos desarrollados por docentes para ser trabajados y debatidos en las materias que dictan; la colección Libros de Filo (10) está dedicada a la generación de espacios para el debate disciplinar de los departamentos, tiene como objetivo dar a conocer la situación actual de las carreras de grado y las entregas las planifican cada uno de los departamentos; la colección Saberes (111) publica textos que reflejan los resultados de las investigaciones, y fue creada para difundir las desarrolladas en la Facultad; y por último, la colección Puentes (9) que da cuenta de las actividades de extensión, dedicada a visibilizar los resultados del trabajo de los distintos equipos y programas de Extensión Universitaria de la Facultad.

Otra característica formal que se pudo observar es que muchas de las colecciones tienen número de identificación Internacional de Publicaciones en Serie y otros recursos continuados, ISSN, que lo incluyen junto al ISBN que identifica la entrega en particular.

Muchas de las colecciones de la década de 1990 manifiestan la intención de publicar los avances y resultados de las investigaciones que desarrollan los Institutos, 
es el caso de los Cuadernos del Instituto Ravignani, Cuadernos de Investigación, Textos o Estudios, Nuestra América y Cuadernos del GETEA. Otras surgieron con la intención de dar a conocer las distintas ponencias de congresos o seminarios dictados en un área temática o disciplinas como ocurre con la Colección Formación de Formadores y Estudios de Teatro Argentino e Iberoamericano. Y algunas más solamente agrupan distintos textos que se producen en un ámbito disciplinario como ocurre con Territorio y Cuadernos de Bibliotecología. También está el caso de la serie Documentos de trabajo que reúne ensayos y traducciones destinados a la discusión y reflexión crítica de los grupos de investigación.

Mención aparte merece la Colección de libros raros, olvidados y curiosos que tuvo como objetivo hacer ediciones traducidas, anotadas y/o con estudios preliminares de una selección de textos que se encuentran en la colección del Tesoro de la Biblioteca Central de la Facultad. Para publicar cada título se reunió un equipo diferente de docentes, estudiantes becarios y graduados dirigidos por el director de la colección. Otra particularidad de esta iniciativa es que sus tapas fueron de las primeras que se diseñaron en la Facultad aplicando el concepto de diseño como retórica visual. Se publicaron 13 volúmenes entre 1995 y 2003.

Otro aspecto que se manifestó al analizar las colecciones de esta década es la falta de normalización al momento de imprimir su nombre en los textos impresos. Hay colecciones que se dividen o incluyen subseries con la intención de agrupar más específicamente las entregas. Como es el caso de la Colección Sinsonte: Homenajes y Ensayos del Instituto de Literatura Hispanoamericana que reúne la serie Sinsonte (2), la serie de la Vigilia (2), la serie Homenaje (3) y la serie Ensayos con la intención de publicar textos poco frecuentes o desconocidos de autores latinoamericanos, acompañados de presentaciones y estudios críticos. Otro caso es el de Hipótesis y Discusiones (18) que a partir de la entrega 10 inaugura la sub-serie Documentos (1) con la intención de rescatar textos inéditos o fuera de circulación de la literatura para relanzar dentro de esta subserie.

Un caso particular es la subdivisión que hace la colección Cuadernos de Investigación del IICE en donde agrupa las 13 entregas (1988 a 1996) con la denominación de Áreas, tales como Lingüistica y Educación, Universidad, Jornadas y congresos, Desarrollo socioculturaly Educación permanente, entre otras.

El panorama en la década de 2010 se presenta mucho más homogéneo lo que podría estar indicando un cambio en las estrategias al momento de conformar las colecciones. Esto lo evidencia la existencia de las 4 colecciones ya mencionadas creadas o desarrolladas por la Subsecretaría de Publicaciones -Saberes, Libros de Cátedra, Libros de Filo y Puentes- que reflejan el trabajo intelectual de la institución con base a ejes planificados y con objetivos específicos.

Destacan en esta década las 14 entregas de la colección Textos y Estudios del Instituto de Filología Clásica que se inició en 1994 e incluye textos de fácil acceso que ayudan en la comprensión de los estudios medievales, además del filológico, ya que proveen trabajos de investigación, ediciones y traducciones de los investigadores del instituto y externos a él.

Hay un grupo de colecciones que se iniciaron a fines de la década de 1980 o en la década de 1990 y se sostienen en la de 2010 tales como Hipótesis y discusiones (6), Cuadernos de Bibliotecología (5) y Cuadernos de territorio (4). Por otra parte hay 9-Colección Sol de Noche, Nuestra América, Antorchas o Memoria, verdad y justicia, entre otras- que han tenido solo una entrega a lo largo de la década y, al momento del análisis, 5 de ellas no han publicado nada desde 2015. Por último, un comportamiento similar con 2 entregas a lo largo de la década se observó en aquellas que tienen una propuesta 
diferente a las típicas de la Facultad, tales como Colección Narrativas, Historia dibujada y Reediciones imprescindibles.

Otro aspecto de la Materialidad lo estudiamos en distintas variables físicas que conforman el peritexto. En cuanto a la mención en el pie de imprenta de "Universidad de Buenos Aires | Facultad de Filosofía y Letras" tal como lo exigen los reglamentos de publicaciones, se pudo observar que las publicaciones de estas dos décadas cumplen este requisito. La forma de representar el pie de imprenta tiene variaciones que se pueden ver en la Figura 2. Por caso está la mención de la Universidad y Facultad (1990: 36,08\% y 2010: 78,86\%). Además, cabe acotar que, en la década de 2000, se agregó un Sello editorial denominado eFFL que se suma en el pie de imprenta a partir de esa fecha.

En otras publicaciones el pie de imprenta adiciona a la mención de Universidad y Facultad, la del Instituto, Secretaría o Departamento que gestionaron la publicación. Se identificó un cambio entre las dos décadas (1990: 61,74\% y 2010: 6,69\%), que podría marcar un nuevo perfil de la política editora donde las secciones, institutos o departamentos ceden la mención a la forma genérica de Universidad y Facultad en busca de una identidad unívoca. Además, hay cerca de un $7 \%$ de libros que mencionan solamente la dependencia que generó la publicación (Instituto, Secretaría, etc.) y, contrario a lo que exige el Reglamento de publicaciones, no incluyen el nombre de la Universidad y Facultad.

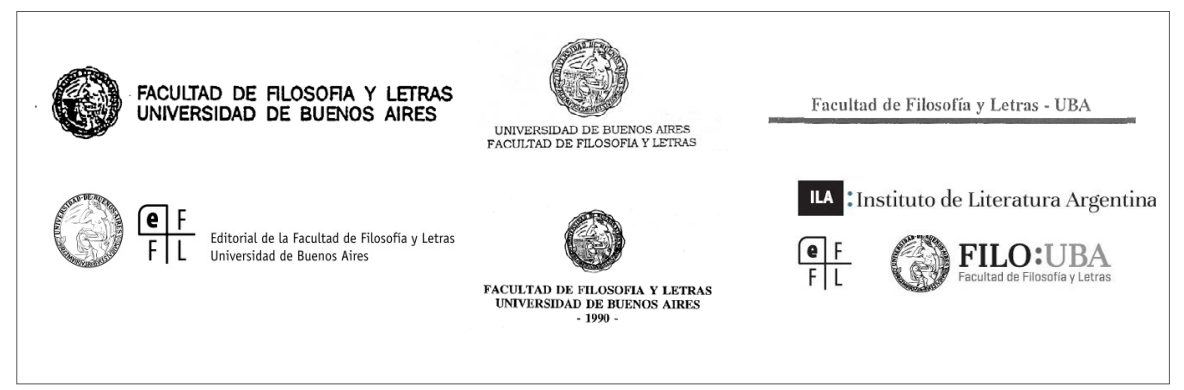

Con el propósito de fortalecer acciones de divulgación científica y prestar un servicio a la comunidad, en 2015 se crea una nueva línea editorial denominada EUFYL, dirigida a los lectores no académicos interesados en los grandes temas de la cultura y disponibles en librerías externas. Un $6 \%$ se publicó con este sello.

Las co-ediciones en la década de 1990 suman un poco más del $27 \%$ del total de lo publicado y, en su mayoría, lo hacen con instituciones. En cambio, en la de 2010 resalta que las coediciones disminuyen al 10\%, también en su mayoría con instituciones.

Cuando se analizaron las tapas o cubiertas se pudo observar una variación importante entre las dos décadas en estudio. En la década de 1990 predominan las tapas solo con texto (34\%), en cambio en la década de 2010 solo un $6,78 \%$ son textuales sin diseño alguno. Por el contrario, la década de 2010 se caracteriza por una presentación atractiva, donde un $35,71 \%$ incluye algún tipo de diseño, mientras que en la década de 1990 lo hace solo un $30 \%$ de lo editado. También, hay tapas o cubiertas que contienen una fotografía alusiva al tema tratado, solo un $13,71 \%$ en la década de 1990 ; en cambio, el uso de fotografía aumenta a un $35,71 \%$ en la de 2010 (Gráfico 7). Estas modificaciones en la presentación gráfica de las ediciones están relacionadas con la
Figura 2: Variaciones del pie de imprenta 
Gráfico 7. Distribución por tipos de tapas y ejemplos (1990-2010)
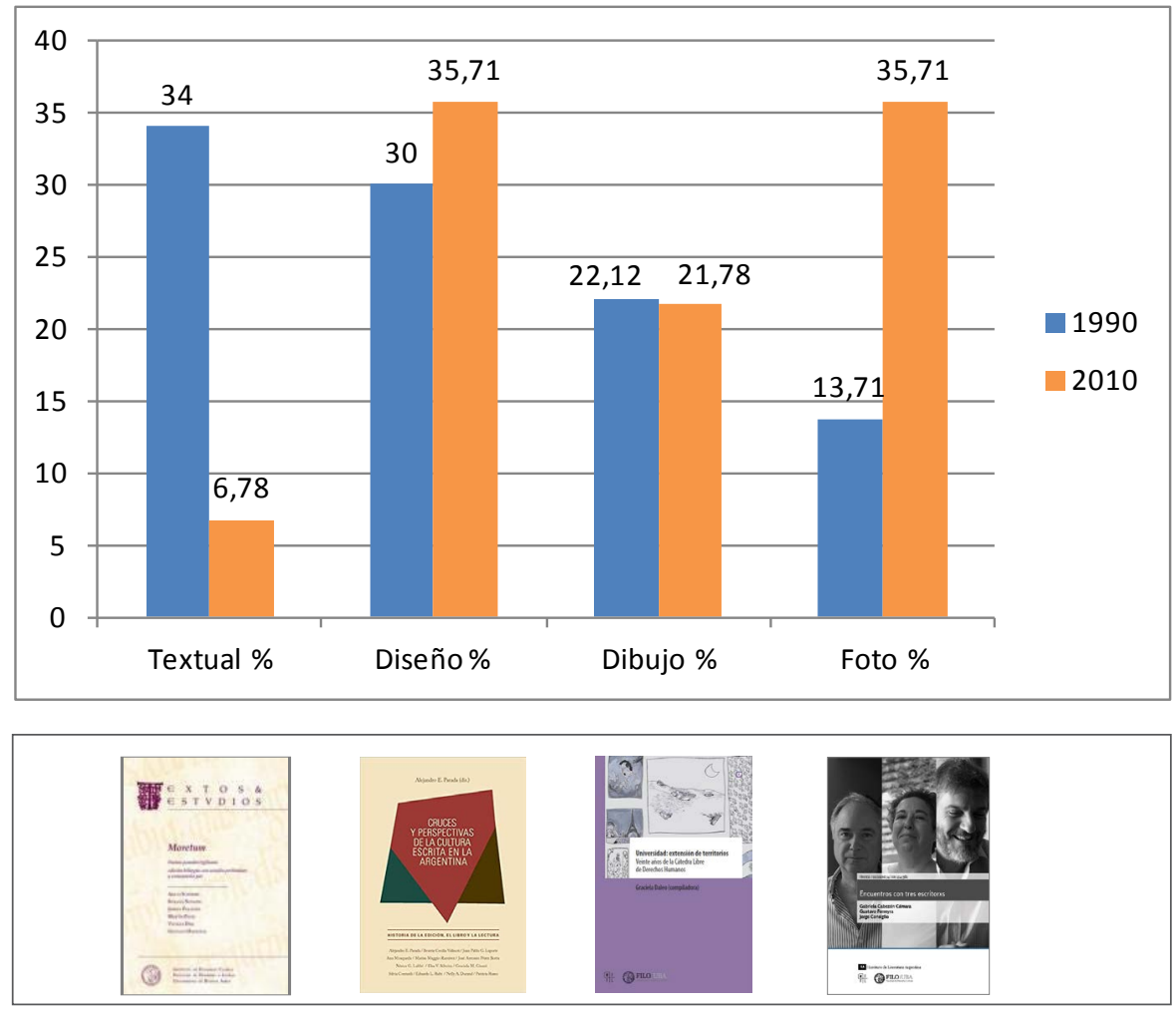

Fuente: elaboración propia

profesionalización del área, con las nuevas tecnologías de impresión y la incorporación de talleres externos en el proceso.

Por otro lado, se puede observar que el soporte principal continúa siendo el impreso, aunque muchos de los libros en esa materialidad tienen su versión en digital y están disponibles en el catálogo del sitio web de la Subsecretaría de Publicaciones de Filo. Solamente un $1,76 \%$ de las publicaciones de la década 2010 fue publicado únicamente en versión digital y un $0,42 \%$ en la de 1990 ; en menor proporción, se utilizaron CD-Rom en la década de 2010. En cuanto a la media de la extensión en páginas, se observa un aumento del $90 \%$, ya que el promedio de la década de 1990 es de 144 y el de 2010 llega a 263 páginas.

La Facultad sigue manifestando una preferencia por publicar sus libros en soporte papel, si bien han sumado la versión digital de acceso libre (PDF) fundamentalmente en la década de 2010, aún son escasos los libros publicados únicamente en archivo digital.

En cuanto a la perspectiva de Difusión-Circulación nos concentramos en la década de 2010 para analizar la difusión que la Institución hace, en conjunto con su comunidad, para divulgar la producción académica y encontramos que la promoción en espacios digitales no propios (399 entradas, tales como páginas web, blogs, facebook y twitter, etc.) son los canales más representados; le siguen las difusiones mediante los canales propios de la Facultad (323).

La publicación de reseñas en revistas de extensión de la Facultad, en revistas académicas propias y en revistas académicas de otras instituciones conformaron el otro eje de análisis; se pudo observar un claro predominio de las reseñas en revistas académicas 
externas, en esta instancia se localizaron 111 reseñas, donde la mayoría de los textos tienen una o dos representaciones y solo en un caso localizamos que un libro tenía más de 10 reseñas.

Otra forma de difusión analizada es la presentación del libro como encuentro presencial académico característico del quehacer universitario. Estos eventos se detectaron con más frecuencia en la propia institución (53); no obstante, varios de ellos (41) se llevaron a cabo en espacios externos. Se encontró un caso de presentación de un libro de un tema de interés público y transversal que se transmitió en un noticiero; en otros casos (3) donde el video de la presentación se publicó en YouTube y, finalmente, se localizaron 3 presentaciones virtuales.

También se ubicaron 61 anuncios y reseñas en diarios o agencias de noticias y 15 entrevistas realizadas en el contexto de la publicación de un libro.

En cuanto a la observación de la circulación de los textos, al momento de realizar la búsqueda en el catálogo colectivo WorldCat consideramos las dos décadas y se pudo observar, en ambos casos, un valor considerable de presencia de la producción en las bibliotecas que conforman este catálogo. De los 230 libros publicados en la década de 1990 se localizaron 180 de ellos, lo que muestra una visibilidad del $78,26 \%$. Y con respecto a los 284 libros publicados en la década de 2010 dio como resultado que 166 de ellos se encuentran registrados lo que da una visibilidad de $58,45 \%$.

Este panorama de la difusión y circulación de las publicaciones de la Facultad nos permitió identificar algunas conductas habituales de esta casa de estudio y los datos obtenidos podrán ser analizados desde distintas aproximaciones.

\section{Consideraciones finales}

A modo de cierre de este análisis se pueden ensayar algunas conclusiones generales. Un primer resultado evidencia que en las tres perspectivas de análisis se presentaron variaciones, mayores o menores, que tienden a reflejar en esta institución los cambios propios de la edición universitaria en las décadas estudiadas.

En primer término, se observa un incremento de la producción del $20 \%$ en el período de 2010 con respecto al de 1990 en concordancia con el crecimiento propio de la institución y de su comunidad y, quizás, relacionado con la institucionalización de los proyectos de investigación que, entre sus exigencias, contempla la publicación constante. Esto también lo muestra el crecimiento de un $25 \%$ de los textos científicos derivados de investigaciones acreditadas.

En cuanto a la autoría, la monoautoría predominante en la década de 1990 tiene una disminución del $25 \%$ con respecto al decenio de 2010 , esto podría ser un indicio de la tendencia a producir textos en colaboración en el contexto de una valoración del trabajo en equipos multidisciplinarios e interinstitucionales característicos de esta década. En consonancia se observó el aumento del $25 \%$ de la autoría en colaboración en la década de 2010, además de un incremento significativo de la cantidad de autores que participan en las obras colaborativas y de los distintos tipos de autorías.

En cuanto a la pertenencia institucional de los autores, sigue manteniendo el mismo comportamiento de una mayoría absoluta de los institucionales; sin embargo, se nota un incremento del $15 \%$ de textos con autoría mixta que refleja la colaboración interinstitucional. 
En cuanto a los temas, en primer lugar, se observan tanto incrementos como disminuciones en las dos décadas en casi todas las disciplinas, lo que refleja una institución muy dinámica, aunque para interpretar estos datos será necesario relacionarlos con otros acontecimientos dentro de la comunidad y la sociedad. Es claro que algunas disciplinas son más fuertes que otras al momento de conformar el catálogo editorial de esta Facultad, pero también se visualiza la permanencia de las aparentemente más débiles en esta ruta de publicaciones.

En las dos décadas se comienza a vislumbrar una tendencia a usar títulos más convocantes y atractivos con el fin de llegar a otros públicos y, paulatinamente, abandonar los títulos puramente académicos. Como consecuencia de esto, aumenta el uso de subtítulos que permiten orientar sobre el tema del texto. Estos cambios podrían deberse a una estrategia editora para atraer a lectores externos a la institución y trascender las fronteras para llegar a otros ámbitos.

En cuanto a las colecciones se mostró que su uso es una práctica consolidada dentro de la planificación editorial ya que alrededor del $80 \%$ de los libros publicados lo hacen dentro del diseño de una colección. Por otra parte, se constataron cambios importantes entre las décadas en cuanto a la cantidad de colecciones; la década de 1990 se caracteriza por tener una notable dispersión de las publicaciones en 52 series reconocidas. En cambio, en la década de 2010 se identificaron 22 colecciones que agrupan la producción y se pudo observar que 4 de ellas concentran el $64 \%$ de todo lo publicado mostrando una clara intencionalidad de contrarrestar la dispersión.

Se pudo observar que efectivamente hay series y colecciones tanto especializadas como generales en ambas décadas. En líneas generales, en la década de 1990 prevalecen las colecciones de los Institutos que se caracterizan por reunir la producción de sus investigadores siendo este el eje que agrupa las entregas. En cambio, en la década de 2010, si bien mantienen vigencia algunas diagramadas por los Institutos, predominan las colecciones gestionadas por la Subsecretaria de Publicaciones que agrupa las ediciones en 4 ejes principales (Cátedras, departamentos, investigación y extensión).

Si nos referimos a la materialidad destaca la preponderancia del soporte impreso y, en muchos casos, tienen su versión en digital. Además, se evidenció que se duplicó la media de páginas de los libros; esto podría explicarse con el incremento de textos colaborativos, donde al aumentar la cantidad de autores que colaboran aumentan las páginas.

En la última década se aprecia una clara tendencia a normalizar el sello editorial en el pie de imprenta; lo que demuestra una mayor profesionalización al otorgar una identidad editorial unívoca. Las tapas presentan un cambio significativo al abandonar las cubiertas puramente textuales, características de la década de 1990, e incorporar color, ilustraciones y fotos en busca de diseños más atractivos.

En cuanto a la circulación y difusión, a través de las diferentes variables que se analizaron en esta perspectiva se encontró una considerable difusión y circulación si bien no se vislumbró una política explícita y sustentable en esta área.

Se identificaron como predominantes dos instancias de difusión arraigadas en la comunidad como lo son las reseñas de libros tanto en revistas externas como propias, corroborando la valoración por parte de la comunidad de este tipo de difusión. Por otra parte, también se pudo observar en WorldCat una significativa presencia de la producción en los catálogos de bibliotecas internacionales que muestra, en cierta forma, una circulación afianzada a través del canje e intercambios académicos. Además, se mantienen las presentaciones de libros, si bien predominan las realizadas en 
la propia institución, también aparecen las de ámbitos académicos externos y, de a poco, se suman las realizadas de manera virtual.

Analizar el devenir de un catálogo de una editorial universitaria ha sido un desafío que abre nuevas puertas e interrogantes y será necesario sumarle a este análisis otras décadas que amplíen la visión de las tendencias o aplicar distintas periodizaciones que muestren otros matices. En nuestro caso se observó una constante de un valor de entre un 20 y $25 \%$ de cambios en las variables estudiadas, si se tiene en cuenta que entre 1990 y 2019 pasaron 30 años, este porcentaje pareciera estar indicando una lentitud en los cambios.

La Facultad es una institución dinámica y compleja; no obstante, se pudo observar una clara intención de incorporar cambios y nuevas tendencias reflejadas en su catálogo editorial, si bien tiende a integrarlas de manera paulatina, muestra un diálogo con las demandas de la ciudadanía como entidad pública de difusión de sus saberes.

Con este estudio cuantitativo se trató de brindar un escenario para analizar las transformaciones en la forma de publicar textos en la Facultad en esos años, muchos de ellos influenciados por un contexto social que incidió en el catálogo editorial, más allá de las demandas de la enseñanza y la investigación, y le ha permitido facilitar el acceso al conocimiento a la comunidad que la sostiene. 


\section{Referencias bibliográficas}

》 Anaya Rosique, Jesús. 1989. La actividad editorial universitaria en México: nociones y aproximaciones. En Libros de México. Vol. 15, 37-46.

"Bonacci, Juan Martín. 2018. Entre la academia y el mercado editorial. La edición universitaria de libros de sociología en la Argentina tras el retorno a la democracia (1983-1995). En Prismas. Revista de historia intelectual. Vol. 22, no. 2, 167-172.<http://www.scielo.org.ar/scielo.php?script=sci_arttext\&pid=S1852$04992018000200249 \& \operatorname{lng}=e s \& n r m=i s o \&$ tlng=es $>$ [Consulta: 30 noviembre 2021].

»Centeno, Rafael. 2012. Circulación y fronteras comerciales del libro universitario. En Primer Coloquio Argentino de Estudios sobre el Libro y la Edición (1a: 31 de octubre al 2 de noviembre de 2012: La Plata). Trabajos presentados. La Plata: Instituto de Investigaciones en Humanidades y Ciencias Sociales (UNLP - CONICET) <http://coloquiolibroyedicion.fahce.unlp.edu.ar/actas/Centeno.pdf/view> [Consulta: 30 noviembre 2021].

»Costa, María Eugenia y Marina Garone Gravier. 2020. Reflexiones sobre la noción de catálogo y colección editorial. Dispositivos y estrategias para la producción de sentidos en el mundo del libro. En Palabra Clave (La Plata). Vol. 9, no. 2, eo82 <https://doi.org/10.24215/18539912eo82>

»Darnton, Robert. 2010. La edición: una estrategia de supervivencia para autores académicos. En Darnton, Robert. El beso de Lamourette. Reflexiones sobre historia cultural. México: Fondo de Cultura Económica. p. 105-1113.

»De Sagastizábal, Leandro. 2002. Informe sobre la situación y perspectivas de las editoriales universitarias en Argentina. BuenosAires: IESALC-UNESCO; Ministerio de Educación, Ciencia y Tecnología, Secretaría de Políticas Universitarias.

»Dujovne, Alejandro. 2017. Campo editorial y traducción. Valor y formación de valor de la traducción en las ciencias sociales y humanas en Argentina (19902011). En Desarrollo Económico. Revista de CienciasSociales. Vol. 56, no. 220, 443-468<https://ri.conicet.gov.ar/handle/11336/46153> [Consulta: 30 noviembre 2021].

"Dujovne, Alejandro. 2018. “Efectos de lectura”. Problemas y propuestas para el estudio de las relaciones entre campo editorial y campo académico en las Ciencias Sociales y Humanas. En Prismas. Revista de historia intelectual. Vol. 22, no. 2, 261-267. <http://www.scielo.org.ar/scielo.php?script=sci_arttext\&pid=S185204992018000200261\&lng=es\&nrm=iso> [Consulta: 30 noviembre 2021].

»Dujovne, Alejandro. 2019. Ampliación y límites estructurales de la edición universitaria pública argentina. Un análisis de la producción y distribución editorial entre 2014 y 2019. En Telar. No. 23, 91-116. <http://revistatelar.ct.unt.edu.ar/ index.php/revistatelar/article/view/448>[Consulta: 30 noviembre 2021].

»Genette, Gerard. 2001. Umbrales. Buenos Aires: Siglo XXI.

»Los libros de Filo: 120 años publicando: versión preliminar. 2016. Giunti, Graciela. M., Silvia Contardi e Ivalú Ramírez Ibarra, comp. 1aed.- Ciudad Autónoma de Buenos Aires: Editorial de la Facultad de Filosofía y Letras. Universidad de Buenos Aires. (Cuadernos de Bibliotecología; 25). <http://publicaciones.filo.uba. ar/los-libros-de-filo> [Consulta:20 octubre 2021]. 
»Libros de Filo:122 años publicando: edición corregida, ampliada y actualizada. 2019. Giunti, Graciela. M., Silvia Contardi e Ivalú Ramírez Ibarra, comp. Ciudad Autónoma de Buenos Aires: Editorial de la Facultad de Filosofía y Letras. Universidad de Buenos Aires. (Cuadernos de Bibliotecología; 27). <http://publicaciones.filo.uba.ar/libros-de-filo-122-a\%C $3 \%$ B10s-publicando> [Consulta:20 octubre 2021].

"López Valdés, Mauricio. 2006. El quehacer del editor universitario. En La Gaceta del Fondo de Cultura Económica. No. 428, 2-6.

»Martínez de Sousa, José. 2004. Diccionario de bibliología y ciencias afines. $3^{a}$. ed. Gijón: Trea.

» Mihal, Ivana. 2020. La edición universitaria argentina a la luz de la Feria del Libro de Guadalajara: acerca de la internacionalización y digitalización. En Cuadernos del Centro de Estudios en Diseño y Comunicación. No. 85, 48-69. <https:// doi.org/10.18682/cdc.vi85.3751>

" Mihal, Ivana. 2021. Editoriales universitarias y mercado. Tendencias de comercialización en feria. En Información, cultura y sociedad. No. 44, 117-142. <https:// doi.org/10.34096/ics.i44.8215>

"Navarro, Federico y Ana Brown. 2014. Lectura y escritura de textos académicos. Conceptos básicos. En Manual de escritura para carreras de Humanidades. Navarro, Federico, coord. Buenos Aires: Universidad de Buenos Aires. Facultad de Filosofía y Letras. p. 55-100.

»Pérez Lasheras, Antonio. 2007. La edición universitaria en el siglo XXI. En Polo Pujadas, Magda, coord. Innovación y retos de la edición universitaria. Madrid: UNE, Unión de Editoriales Universitarias Españolas. p. 37-44.

»Piccolini, Patricia. 2006. La selección de originales en la edición universitaria. En LaGaceta del Fondo de Cultura Económica. No. 428, 6-10.

»Premat, Julio. 2006. El autor: orientación teórica y bibliográfica. En Cuadernos LIRICO. No. 1, 311-322. <https://doi.org/10.400o/lirico.824>

"Silva, Gustavo A. 2005. La autoría múltiple y la autoría injustificada en los artículos científicos. En Investigación en Salud. Vol. 7, no. 2, 84-90. <https://www. redalyc.org/pdf/142/14270202.pdf> [Consulta: 20 octubre 2021].

"Sorá, Gustavo y Alejandro Dujovne. 2018. Translating Western Social and Human Sciences in Argentina: A comparative study of translations from French, English, German, Italian and Portuguese. En Heilbron, Johan, Gustavo Sorá y Thibaud Boncourt, eds. The Social and Human Sciences in a Global Perspective. Londres: Palgrave Macmillan.

» Torres Ripa, Javier. 2007. El libro en entornos cambiantes. En Polo Pujadas, Magda, coord. Innovación y retos de la edición universitaria. Madrid: UNE, Unión de Editoriales Universitarias españolas. p.61-69.

» Úbeda, Jordi. 2007. La edición académica en España. En Polo Pujadas, Magda, coord. Innovación y retos de la edición universitaria. Madrid: UNE, Unión de Editoriales Universitarias españolas. p. 45-50.

»Universidad de Buenos Aires. 1960. Estatuto de la Universidad de Buenos Aires. <http://www.uba.ar/download/institucional/uba/9-32.pdf> [Consulta:20 octubre 2021]. 
